\title{
INHALTSVERZE ICHNIS
}

Namenverzeichnis

II-V

\section{Allgemeines:}

Geschichte, Grundlagenwissenschaften, Jahresberichte, Statistik $2005-2006$

Allgemeine Tierzucht :

Entwicklungslehre, Organe des Tierkörpers, Genetik, Fortpflanzung, Züchtung, Wachstum und Entwicklung, Ökologie einschließlich Haltung und Pflege, Nutzung und Qualität tierischer Erzeugnisse, Inhaltsstoffe tierischer Erzeugnisse, Tierpsychologie, Maßnahmen zur Förderung der Tierzucht. . . . . . 2006-2058

Sperielle Großtierzucht:

Pferde, Rinder, Schweine, Schafe...................... 2058-2091

Spezielle Kleintierucht:

Ziegen, Geflügel, Kaninchen, Pelztiere, Hunde, Bienen, Seidenraupen . . . . . 2091-2115

\section{Tierernährung:}

Chemische Bestandteile des Tierkörpers und der Futtermittel, Untersuchungsund Versuchsmethodik, Ernährungsphysiologie, Verwertung der Nährstoffe und Futtermittel, Ernährungsstörungen und Mangelkrankheiten, Bewertung der Futterstoffe, Fütterung der landwirtschaftlichen Nutztiere.

\section{Futtermittelkunde:}

Futterstoffe, ihre Beeinflussung, Konservierung und Zubereitung, die ein-

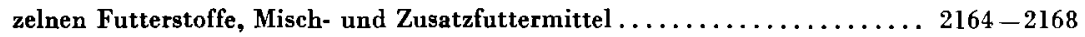

\section{Fischerei}

Biologie, Lebensraum, Fischereiwirtschaft, Beeinflussung der Fischerei durch die Umwelt, Fischkrankheiten, Fischverarbeitung, Fanggeräte, Organisation und Planung, Fischereirecht, fischereiliche Wirtschaftsgeographie ... 2169-2216 